\title{
Digitalisation of Enterprises Brings New Opportunities to Traditional Management Control
}

\section{Krister Bredmar}

School of Business and Economics, Linnaeus University, Sweden

\section{Abstract}

Background: Advanced information systems have changed the way managers work with planning and performance measurement. Traditional management control concepts such as efficiency have changed in meaning due to these information systems. Objectives: The main purpose behind this paper is to try to understand how a new managerial context is shaped and re-shaped by new information systems that constitute a digital enterprise. Methods/Approach: Three different cases are presented and analysed. Results: The new managerial function of advanced information systems is presented through the three cases. Conclusions: The digitalisation debate and agenda need to develop an even deeper understanding of how digital initiatives affect organisations. This is possible by dealing with concepts such as the digital enterprise, which integrates digital technical solutions with organisational challenges and management control intent.

Keywords: information systems; management control; digital enterprise

JEL classification: M15

Paper type: Case Study

Received: Mar 01, 2017

Accepted: Jun 15, 2017

Citation: Bredmar, K. (2017), "Digitalisation of Enterprises Brings New Opportunities to Traditional Management Control", Business Systems Research, Vol. 8, No. 2, pp. 115125.

DOI: $10.1515 /$ bsrj-2017-0020

\section{Introduction}

The introduction of new technical solutions usually brings with it opportunities to work in different ways. This is especially true when it comes to how computers are used in organisations. Repetitive tasks are automated and transactional-based work, usually with huge volumes, is run by computerised systems. Through this more extensive capturing, storing and analysing of data there also comes the opportunity to plan for and monitor a special section of a larger work process in detail (Alter, 2008), as well as the ability to manage in automated, micro-managed ways (Davenport, 2013). Traditionally, such technological solutions have been used in manufacturing contexts where robots deliver the exact product over and over again. In recent years, through the advanced use of data analytical tools such as big data analysis and the 
Internet of things, managerial optimisation has expanded to other sectors where the bases for decisions have become more extensive (Laudon and Laudon, 2004).

The concept management control is in many ways an elusive phenomenon. It is hard to find a distinct and all-inclusive definition that grasps the entire meaning of what managers do. From one point of view, management control deals with all the techniques used to plan and monitor operations such as budgets and cost calculations (Emmanuel et al., 1990). From another, it is about the behaviour in an organisation and how managers motivate workforces to do their best; how the environments created offer the opportunity to reach organisational goals (Bredmar, 2016). Yet again from another point of view, management control is about measuring performance in different forms; both when it comes to profitability, but also when it comes to dimensions such as customer experience, efficient internal processes and the ability to change (Kaplan and Norton, 1995). Altogether, management control works as an umbrella concept that includes several different dimensions which deal with how managers work within an enterprise, especially when it comes to planning for an operation and monitoring its outcome (Euske, 1984).

One important source of information that is frequently used by managers and gives them the ability both to plan and monitor a business is double entry bookkeeping (Belfo and Trigo, 2013). However, the technical support for working with accounting issues have gone through several phases. At the outset, and one could say all the way to the 1980-1990s, accounting work was done on paper in large ledgers. This was the original technical solution that the accountant used to gather, store and analyse financial data, transforming it into manageable financial information. When computers entered businesses, one of the first tasks or techniques they were used for was accounting. Different forms of accounting software ran volumes of transactional-based accounting material, and through this new technical solution new forms of analysis could be realised in seconds (Belfo and Trigo, 2013). In a third phase, the phase that businesses have been in for some years now, accounting software has been integrated into other forms of corporate information systems, usually called Enterprise Resource Planning Systems (ERP) (Bradford, 2010). As such, accounting systems are no longer standalone, operating and working with one form of data, but are now integrated with several data sources, one of which is accounting.

The new information systems still do what traditional information systems are supposed to do; that is, gather, store and analyse data before distributing the information to those needing it (Alter, 1999). However, in its most extreme form, these procedures are done in a broader, more detailed, speedier way, making it possible to manage differently and more effectively with new technical solutions. The new 'ERP' systems challenge the way management control is conducted in an organisation, forcing managers to work in differently if they want to take advantage of all the possibilities brought by the systems. Traditional accounting tasks are now set in another context where it is not only the financial dimension, which is interesting to monitor, but also all the performance dimensions that lead to the financial statements.

The digital enterprise, in many ways, creates a new context for management control to operate in. It becomes not only possible to talk about the resources needed for a specific unit to be able to reach a certain goal, but in a deeper way, it also becomes possible to talk about translating strategy into discrete actions. As critical resources can be monitored in what could be described as a micromanagement way, any deviations or unsatisfactory performances can be 
immediately rectified, in some cases without a management decision. Some of the new data-analytical based systems could even alter goals and targets as the organisation learns and has new experiences. Although these examples are currently rare. The main purpose behind this paper is to try to understand how a new managerial context is shaped and re-shaped by new information systems that constitute the digital enterprise. This third phase of accounting information systems offers both an opportunity and challenge to managers when it comes to the simple task of management control.

\section{Theoretical frame of reference}

One of the earliest authors within management control was Robert Anthony (1965). In his book "Planning and control systems: a framework for analysis" (1965) he discusses three different, hierarchal levels in an organisation which in different ways have to do with management. At the highest level, strategic planning objectives are decided upon, and different policies to govern operations and resources are established. At the lowest level of operational control, the organisation's different operational tasks are in focus, measured through concepts such as effectiveness and efficiency. In between these levels lies the concept, or phenomena, of management control which deals with how resources are used. It is described as having purely planning and control functions; two functions that can be considered two sides of the same coin (Emmanuel et al., 1990).

In his early definitions, Anthony (1965) described management control as something that could be understood from three different perspectives. Firstly, there is a manager who gets things done in collaboration with other organisational personnel. Thus, from one perspective management control is a social phenomenon that takes place within an organisation. Secondly, there are some predefined objectives and policies that have been established at the strategic planning level which then guide the work occurring at the lower levels, especially at the level of management control. Thirdly, performance is measured and monitored through effectiveness and efficiency measures of the critical resources and other planned factors. Thus, at the centre of management control are resources, the social context, organisational objectives and performance measures.

Other management control definitions include aspects that are usually associated with information systems theories. Horngren, Sundem and Stratton (1996), for example, talk about management accounting as a process that identifies, measures, accumulates, analyses, prepares, interprets and communicates information which assists executives. This is close to definitions of information systems such as Alters (1999, p. 4) where "... an information system is a work system that uses information technology to capture, transmit, store, retrieve, manipulate, or display information, thereby supporting other work system[s]". Hence, in one way or another, management control is closely linked to information systems, making information in general and financial information in particular common denominators of managerial work. From another perspective, advanced information systems could or should be understood within a management control context in order to understand their usefulness or value.

Management control, on the other hand, needs to be understood within an organisational context (Flamholtz, 1996). Control then becomes something that could be described as a tool that managers use to get a sense of order or structure. Even though management control is needed and could be understood as something technically applicable, at the same time it is elusive and hard to grasp. This is especially true when it comes to the effects or results it brings to an 
organisation which have mainly to do with the fact that most organisations are built on humans who, from time to time, are difficult to both understand and manage. Flamholtz (1996) concludes that management control is about motivating people, coordinating efforts and providing information. Through the use of information at the lower level of operation there is an opportunity to work with control in an autonomic way, without the constant supervision of what is going on in an organisation.

\section{Methodology}

This study is based on a multiple-case methodology (Yin, 1994). The empirical material used for this study comes from case-descriptions that different information system vendors have presented as the means of showcasing their products. This is not unproblematic as the purpose behind the case description is to convince the receiver of the software's excellence. However, this issue has been taken into consideration both in the presentation of the results, as well as with regard to the conclusions and analyses. After reviewing the different case descriptions, those that closely describe the user perspective were chosen, three in total. This also presents a deeper understanding of the software's effects in the studied organisations. Even though the vendors had different purposes behind the case descriptions, they clearly illustrate how the advanced systems facilitate new opportunities for management when it comes to planning and controlling operations. This makes it possible to talk about the benefits of advanced information systems as tools for managing the digital enterprise, as well as presents a deeper picture of how the management control function has evolved and changed in scope through these systems.

The vendors presented all three cases over promotional videos. Three different vendors - one ERP, one (radio-frequency identification) RFID and one big data analyst - were chosen as they somewhat confirmed the same effects on management control. However, in this paper, these are presented in slightly different ways in order to gain deeper understandings of the field and its contributions to management control. Video films as such have been used successfully in describing and understanding what is going on in a management context (see for example Jönsson, 2004). The information presented in the videos was transcribed and the text then became the empirical material used for the analysis and conclusions (Silverman, 2001). The text thus became transcripts of a conversation which could be compared to the one generated from an interview, and analysed by interpreting what was said and comparing it to different theoretical perspectives (Silverman, 2000).

\section{The digital enterprise and traditional management control issues described through three case studies}

Digital initiatives can bring new opportunities when it comes to running more agile and efficient operations. Companies such as Spotify that have developed new ways of delivering music, or Uber that have made transportation more efficient in several ways, constitute new types of digital enterprises. Further, companies such as Caterpillar, with more than 90 years of experience building heavy duty machines, have installed sensors making it possible to gather information about the machines' performance, which can then be used to plan for maintenance as well as the additional features in upcoming models. This study is based on three cases, which in different ways show how traditional management control functions and tasks have been remodelled through the use of different forms of digital platforms. A common 
denominator is that the advanced information systems are adding a new digital dimension that forms the basis for the digital enterprise. The cases demonstrate that conventional management control work, such as planning and control, is realised more efficiently with the help of the digital systems.

\section{American Apparel}

American Apparel is a company that makes high-quality, fashionable, basic clothes aimed at the urban youth market. It is the largest clothing manufacturer in US and its growth has been explosive expanding from 3 stores in 2003, to more than 300 in 2009. This LA-based company had retail sales worth 341 million dollars in 2008 which was a $62 \%$ increase from 2007. As such, American Apparel could be described as a fashion sensation, comparable to companies such as H\&M and Zara. Still, the company continues its ambitious path and tries to develop all aspects of its business. This is achieved through an expanded product range, but also through advanced systems for supply chain and store management, making the American Apparel an interesting example of a digital enterprise.

American Apparel's success is often measured through its stores' performance and productivity. One example of its development is its boutique style model where there is only one item of each size and colour in the shop floor. In accomplishing this model, or way of managing the store space, efficient and swift replenishment become crucial. From a customer perspective, it is important to know that the size, colour or style desired is represented and possible to buy. As a consequence of the boutique style model, American Apparel stores can handle more items per square metre, thus displaying a wider range of items to the customer. However, on the other hand, the company can be negatively affected if safety stock cannot be located in the store.

There were at least two major challenges that this boutique style model offered. The first regarded tracking the up to $10 \%$ of items that were not represented in the store but were present in the stock. The second regarded finding a way of communicating to the stockroom personnel the replenishment items needed. These challenges were solved through the use of RFID tags offering the store an innovative solution. The system consists of the RFID tags or labels, and printers that print them out as needed, as well as handheld readers and antennas that scan the tags in store with inventory tracker software. In step one, each item had an RFID tag attached to it, and thereafter four inventory tracker stations were established in each store. This way each item could be traced through its tag and the radio-frequency signal which it sent to the readers in different locations throughout the store, making it possible to trace stock deviations and the replenishment needs.

This system is manifested via various stations. In station one - the receiving station each item is registered and added into the back stock. In the next station - the filling station - the employees take items to the sales floor and inform the system through the RFID tags of any movements. Additionally, the system also informs the employees what needs to be taken to the sales floor. The items that the employee brings to the sales floor are validated in the third station to which the system then checks. If there is a deviation between the store's needs and the specific items or amounts, the system tells the employees of this. The final RFID station is the point of sale. Here the tags are read instead of individually scanned, for example through a barcode. The system now knows that the items are leaving the store and need replenishment. The system is designed to tell the employees where the product is at any time in order for the most efficient store management to be achieved. 
This way of developing a boutique style model is focused on the process of replenishment making the store space the critical resource that needs to be used in an efficient way. Even though handling the items from the back stock to the sales floor needs more attention, the RFID system also brings more efficient, time effective handling, for example at the point of sale. As a consequence, the customer is offered more choices on the shop floor and the system also brings forward the ability to maximise sales. The old system of replenishment was built on the idea that employees were counting the items and then replenishing as needed, which of course was time consuming and could involve around 5-6 employees. With the new RFID system, the entire store could be counted and replenished in less than two hours.

As the flow of goods and items is one of a store's critical factors, the digital version of the stock and shop management system offers additional favours, including saved time. The employees could spend more time with the customers and improve customer service. This is also measured through the increased sales where a RFID store generally has $14 \%$ higher sales then a non-RFID one. The advanced supply chain and store management systems through the use of RFID have brought more efficient operations in many dimensions.

\section{Philz Coffee}

Philz Coffee is a San Francisco based coffee shop that has grown to be rather large. The company tries to keep the unique feeling of a small coffee shop but continues to expand by adding newer shops onto the existing portfolio. The founder, Phil Jabner, has had a passion for coffee since childhood. For him, coffee is a way of living, it is the natural end to a meal, and it is something included in both professional and personal meetings. Philz Coffee's ambition is to present a unique authentic coffee experience to its customers and whoever enters its coffee shops.

Some years ago, it decided to take some serious steps toward growth and, in line with that, chose to invest in an integrated information system; an ERP system. One of the system's early values was that the previous accounting system had had a limiting effect on the company, especially when it came to its growth ability. The company not only needed a traditional accounting function, but too a system that could bring more information dimensions and better decision support. As such, the new system supports different business functions. From a supply chain perspective, Philz Coffee can track what is in its stores and deliver to the shops needing refinement. Further, it can track the orders coming in from outside the coffee shops. The system gives management a clear picture of every step from order and fulfilment to billing, providing a one-stop integrated picture of several critical business dimensions. It also, in several ways, brings flexibility to the management function in general, and the management controls function in particular regarding conducting searches and compiling reports, as well as looking into any deviations from plans. The central warehouse supplies 13 retail stores with a minimum of two weekly deliveries of the company's blends. In this way, the coffee is kept as fresh as possible for the customers entering a store. Indeed, this is a supply chain challenge, but through the support of the ERP system, Philz Coffee can maintain a high turnover of goods and items. When the system was newly installed volume tripled over a two-year period.

Through its e-commerce initiative, the company tries to broaden its customer base, a feature which is also supported by the ERP system. The vision is to create an integrated experience with a 360-degree understanding of the customer stored in the information systems. If a customer enters a coffee shop and registers his or her purchase at the cashier and at the same time wants to send some to a relative, this 
should be possible through the system's stored information. Regarding e-commerce, it should also be possible to contact Philz Coffee from a distance through computers and mobile devices, just as easily as if the customer was actually entering the coffee shop. From one perspective, this transition is about supporting a culture which the next generation already lives in, where several different organisational interfaces constitute the entire experience of the enterprise.

Fundamentally, there are problems with planning and agility when firms grow. However, modern technical solutions such as the ERP system mitigate these, making growth something that is possible to accomplish. The system is also tailored to scale up operations when doing the same thing over and over again. From a management perspective, this is about adding increased transactional volume, something that computerised information systems are built to handle. Integrating data from several different parts of an operation also opens up for more advanced analysis, planning and monitoring, and by doing so, builds the base for more efficient operations.

\section{Hamburg Port Authority}

Hamburg Port is the largest in Germany and the second largest in Europe. Its members try to work with a philosophy of innovation when it comes to sustainability and growth. From their points of view, traffic flows are intertwined with trade flows, and making the former work better means creating better opportunities for the latter, summarised as a logistical solution. As the port is responsible for the infrastructure - that is the railroad, roads and everything else to do with transportation within the area - this is an important issue for maintaining efficient operations. The way of looking at infrastructure also includes access to data and information about the port's operations through Bluetooth, hotspots and WLAN, used as and when needed. In 2011, the authority started a project to increase the efficiency of the logistical flow named Smart Port Logistics. In this project, it worked with SAP Hana's platform for gathering, storing and analysing big data in a completely new way. Data were integrated from different transporters, and road data - among others - became the bases for even faster decision-making with the help of advanced data analytics. As such, the ambition was also to find bottle necks and estimate possible breakdowns or needs for increased capacities.

Hamburg Port has an annual turnover of 140 million tonnes, which equals 9 million containers and about 8000 trucks entering through the harbour area daily. By 2030, these numbers are expected to double. Evidently, as the harbour is located in the middle of the city, this becomes a huge challenge due to the fact that there is no land for expansion. One way of dealing with these challenges is to find a way to turn-over the containers more quickly, making core operations more efficient. The process of unloading trucks then comes into focus. Through the advanced data analytics, a smart port logistical service was introduced that was distributed over mobile devices. Through improved routes, ideal times were minimised and efficiencies increased.

Due to the intelligent sensors and the work of the Internet of things, optimisation could be accomplished. Data now come from ships, trucks, traffic lights and people, to mention a few, bringing new, expanded opportunities for analyses which provide the bases for more efficient operations. When drivers know precisely when to go where, the waiting times for ships entering the harbour can be minimised. As the volumes are huge, any decrease in waiting time of even a few minutes for each truck would make day-to-day operations far more effective. Estimates say that a decrease in waiting time of 5 minutes for one driver and one tour gives a total of 
5000 hours less truck time each day. Through the telematics traffic system, operations can be planned and controlled in different, novel ways.

An organisation's needs can be met by intelligent sensors as optimisation is anticipated and the entire environment around operations becomes responsive. Further, it becomes easier to respond to arising challenges or opportunities regarding efficiency, as more is incorporated into the system than when solely taking into account what happens in the harbour itself. Generally, the efficiency of the business is also affected as logistical issues such as goods handling in the harbour area affect many large-scale businesses. The project Smart Port Logistics brings insight into how the Internet of things can be used for more efficient logistical operations. With the idea of a smart port, all actors and participants in the harbour can be connected and micro-managed regarding the flow of goods. Through the information systems, information is tailored to specific actors at crucial parts of the entire logistical process.

\section{Discussion - efficiency, uncertainty and information hubs}

The digital enterprise affects operations in an organisation in general, and how management control is achieved in particular. One of the simplest observations is that different forms of digital transformations improve efficiency. This could be about how much time is used for a repetitive task whereby time becomes a critical resource within the organisation. In this respect, planning and handling time more efficiently regard how specific operations can be developed. Another dimension is that managers consequently have to deal less with uncertainty as critical functions or tasks are easily monitored and controlled through advanced information systems. The digital dimension of information systems also provides knowledge about different parts of an operation instantaneously. As such, an advanced information system becomes a one-stop hub for information that almost immediately becomes actionable knowledge for a manager.

At American Apparel, one of the most important key resources is the store area; the more items presented to the customers, the more revenue potential for the store. As such, replenishment work is crucial and one of the key tasks to be managed. Through the initiative with the boutique style model, an advanced RFID based system offers a more efficient way of working with the floor space and replenishing the items sold. The system also offers a quicker way of knowing what items are within the store and corrects deviations. In this way, the system lowers uncertainty when it comes to the items displayed and presented. Moreover, there is also the possibility that employees can obtain correct, timely information about any item and its current volume in both the back store and the shop floor. Hence, the digital initiative here brings several benefits to operations making them run more smoothly and quickly.

For Philz Coffee, the ambition to grow and vision to integrate information about the customer is made possible through integrated data storage and analysis. The advanced ERP information system in many ways deals with what a traditional management control function does. It maximises planning and monitors flows of goods and items, as well as integrates financial issues with other dimensions or operational perspectives. The old accounting software was not suited for expansion and growth, but through a more advanced integrated system, volume increases can be handled. It also offers an integrated information function where different perspectives, both from internal process and customer perspectives, are presented. One way of looking at the contribution of the system is that it offers the possibility to 
add another coffee shop in an agile, swift manner which was one of the purposes behind installing a new system.

In the third case, there is a clear geographical challenge that the digital initiative tries to solve; the harbour needs to expand and double operations but there is no more land to use for this. Therefore, one of the major tasks is to increase efficiency in a dramatic way which is done through the use of modern data analytics and a wide range of sensors and data sources. One traditional challenge for decision support, in order to minimise uncertainty, is to deliver the right information to the right person at the right time. This is, in many ways, something that is needed in order for an operation to be efficient. In the case of Hamburg Port, this is realised through the project Smart Port Logistics and the effects are shown in a more efficient logistical flow. The smart port, therefore, becomes an information hub of its own where planning and monitoring is handled with the supervision of different managers.

For a digital initiative there are several different approaches that can be fruitful to take in order to make the operations run smoothly. In these three cases, three different technical solutions have been the core of the digital initiative, making them the core of the digital enterprise. In the first case, the RFID tags communicate with the system and make management control issues run more efficiently. In the second case, it is an integrated information system that is at the heart of the operation. And, in the final case, there is an advanced data analytical function that works with the enormous volumes of data running through the port's operations. Common to all these systems is that they, in one way or another, need sensors or signals from the operation which are then gathered, stored and presented in different forms. This way of working with advanced data analysis, developed information and enhanced knowledge is at the very heart of a modern digital enterprise.

\section{Conclusions - the digital enterprise}

In this study, it has become obvious that a digital initiative - which forms the basis for the digital enterprise and is built on advanced data-gathering sensors - advances data processing and analysis in new and improved ways. Such initiatives advance interfaces with managers and employees in the organisation, making it easier for the information to become knowledge for the decision maker. This then adds a new level of improved performance to what traditionally constitutes an information system. Here, there is a technical solution that improves something that, from one perspective, already enters the organisation. The technical imperative is critical and equals the digital enterprise. As such, the digital enterprise can be concluded as built upon an advanced information system.

From another perspective, the advanced information system runs in a context. This context is primarily built on a relatively smooth operation that becomes improved with regard to performance via the advanced system. Thus, the system in itself only brings more efficient dimensions of the operation. For the American Apparel case, this was needed in order for the company to be able to display more items in its store; for Philz Coffee, to be able to expand and add coffee shops in an efficient way; and, for Hamburg Port, to be able to increase their operations dramatically without expanding into new geographical areas. The digital enterprise then clearly fits into existing operations. Before Spotify, there was a record industry, and before Uber there were taxi companies. Further, Catterpillar have been building heavy-duty machinery for 90 years, but through the digital initiative put into the existing operations, the traditional business then becomes a digital enterprise. The second conclusion, thus, is that the digital enterprise is built within an established business to make it run more smoothly. 
Throughout industrialisation, manufacturing companies massively grew in number and their core resources were the machines and production lines. These, together with the employees, became tools that managers used to increase productivity and improve performance. By doing so, they concurrently improved profitability. In a similar fashion, modern and advanced information systems have become the tools for managers and employees to use in order to gain improved productivity, efficiency, performance and, therefore, profitability. As such, the final conclusion is that managers must understand how to use the new technological achievements for improving performance leading to improved profitability in the digital enterprise. It is not enough to talk about the digital techniques as such, or the context, the organisation requires the third component of its management to effectively understand how to use these digital tools for improved management control.

Much of the current debate within the digitalisation agenda needs to develop an even deeper understanding of how digital initiatives affect organisations, not only on the surface, but too at the business core. This is possible by dealing with concepts such as the digital enterprise where technical solutions are integrated with organisational challenges and management control intent. It is not enough to talk about these three factors separately anymore, it is crucial for the development of research fields such as digital enterprises and management control to deepen the search for additional knowledge into what the digital initiative brings. Its value is important to understand and is crucial for the next step. Ultimately, the digital initiatives' value can only be understood in its context through the eyes of management.

\section{References}

1. Alter, S. (1999). Information systems, a management perspective, Reading, MA, Addison-Wesley.

2. Alter, S. (2008), "Defining information systems as work systems: implications for the IS field", European Journal of Information Systems, Vol. 17, No. 5, pp. 448-469.

3. Anthony, R. N. (1965). Planning and control systems: a framework for analysis, Boston, Harvard University.

4. Belfo, F., Trigo, A. (2013), "Accounting information systems: Tradition and future directions", Procedia Technology, Vol. 9, pp. 536-546.

5. Bradford, M. (2010). Modern ERP: select, implement, and use today's advanced business systems, North Carolina State University, College of Management.

6. Bredmar, K. (2016). Understanding management control and organisational sense-making, Oxford, Chartridge Books Oxford.

7. Davenport, T. H. (2013). Process innovation: reengineering work through information technology, Boston, MA, Harvard Business Press.

8. Emmanuel, C., Otley, D., Merchant, K. (1990). Accounting for management control, London, Chapman and Hall.

9. Euske, K. J. (1984). Management control: planning, control, measurement, and evaluation, Addison-Wesley.

10. Flamholtz, E. G. (1996). Effective management control Massachusetts, Kluwer Academic Publishers.

11. Horngren, C. T., Sundem, G. L., Stratton, W. O. (1996). Introduction to management accounting, Englewood Cliffs, NJ, Prentice-Hall.

12. Jönsson, S. (2004). Product development - work for premium values, Malmö, Liber.

13. Kaplan, R. S., Norton, D. P. (1995). "Putting the balanced scorecard to work", in Shaw, D. G., Schneier, C. E. Beatty, R. W., Baird, L. S. (Eds.), Performance 
measurement, management and appraisal sourcebook, Amherst, MA, Human Resource Development Press.

14. Laudon, K. C., Laudon, J. P. (2004). Management information systems: managing the digital firm, Upper Saddle River, NJ, Pearson Prentice Hall.

15. Silverman, D. (2000). Doing qualitative research, London, Sage.

16. Silverman, D. (2001). Interpreting qualitative data, London, Sage.

17. Yin, R. K. (1994). Case study research - Design and methods, Thousand Oaks, CA, Sage.

\section{About the author}

Krister Bredmar, PhD, is Associate Professor of Business Administration at the School of Business and Economics, Linnaeus University. His research interests include Digitalisation, Performance Management and Management Control in general. Author can be contacted at krister.bredmar@inu.se. 